\title{
Constituintes químicos voláteis e não-voláteis de Moringa oleifera Lam., Moringaceae
}

\author{
Milena B. Barreto, ${ }^{1}$ João Vito B. de Freitas, ${ }^{1}$ Edilberto R. Silveira, ${ }^{1}$ \\ Antônio Marcos E. Bezerra, ${ }^{2}$ Edson P. Nunes, ${ }^{3}$ Nilce V. Gramosa ${ }^{*}, 1$
}

\author{
${ }^{1}$ Laboratório de Fitoquímica de Plantas Medicinais, Departamento de Química Orgânica e Inorgânica, Centro de \\ Ciências, Universidade Federal do Ceará, Caixa Postal 6021, 60455-760 Fortaleza-CE, Brasil \\ ${ }^{2}$ Departamento de Fitotecnia, Centro de Ciências Agrárias, Universidade Federal do Ceará, \\ Caixa Postal 12168, 60356-001 Fortaleza-CE, Brasil \\ ${ }^{3}$ Departamento de Biologia, Centro de Ciências, Universidade Federal do Ceará, Caixa Postal 6021, \\ 60455-760 Fortaleza-CE, Brasil
}

\begin{abstract}
RESUMO: O estudo fitoquímico do extrato etanólico das folhas de Moringa oleifera Lam., Moringaceae, resultou no isolamento dos derivados benzilnitrilas niazirina, niazirinina e 4-hidroxifenil-acetonitrila, enquanto que das cascas dos frutos somente o octacosano foi obtido. Os óleos essenciais das folhas, flores e frutos foram analisados por cromatografia gasosa acoplada a espectrometria de massa. Os constituintes principais identificados foram: fitol $(21,6 \%)$ e timol $(9,6 \%)$ nas folhas, octadecano $(27,4 \%)$ e ácido hexadecanóico $(18,4 \%)$ nas flores e docosano $(32,7 \%)$ e tetracosano $(24,0 \%)$ nos frutos. As estruturas dos compostos isolados foram identificadas a partir de técnicas espectroscópicas (RMN, IV e EM). A 4-hidroxifenil-acetonitrila está sendo citada pela primeira vez para o gênero Moringa e os óleos essenciais das flores e frutos estão sendo citados pela primeira vez para a espécie $M$. oleifera.
\end{abstract}

Unitermos: Moringa oleifera, Moringaceae, óleos essenciais, nitrilas, niazirina, niazirinina.

\begin{abstract}
Volatile and non-volatile chemical constituents of Moringa oleifera Lam., Moringaceae". Phytochemical analysis of the ethanol extract from leaves of Moringa oleifera Lam., Moringaceae, yield the benzylnitriles: niazirine, niazirinine and 4-hydroxyphenylacetonitrile, while of fruit shells only octacosane was isolated. The essential oils from leaves, flowers and fruits were examined by gas chromatography-mass spectrometry. The major constituents identified were: phytol (21.6\%) and thymol (9.6\%) in the leaves oil, octadecane $(27.4 \%)$ and hexadecanoic acid $(18.4 \%)$ in the flowers oil, docosane $(32.7 \%)$ and tetracosane $(24.0 \%)$ in the fruits oil. The structures of all compounds were identified by spectroscopic analyses (NMR, IR and MS). 4-hydroxyphenylacetonitrile is reported for the first time to the Moringa genus and the essential oils of flowers and fruits are reported for the first time to the species M. oleifera.
\end{abstract}

Keywords: Moringa oleifera, Moringaceae, essential oils, nitriles, niazirine, niazirinine.

\section{INTRODUÇÃO}

O gênero Moringa, único representante da família Moringaceae, é constituído por quatorze espécies amplamente distribuídas nas regiões tropicais do planeta (Anwar et al., 2007; Gassenschmidt et al., 1995; Abdulkarim et al., 2004). Dentre as espécies descritas para o gênero, destaca-se a Moringa oleifera Lam., Moringaceae conhecida popularmente por "moringa", "quiabo-de-quina" ou "lírio" (Matos, 2002). Originária do noroeste da Índia, é amplamente distribuída nos países da Ásia e da África (Makkar \& Becker, 1996; Matos, 2002; Bezerra et al., 2004).

No Brasil, a moringa foi introduzida como planta ornamental por volta de 1950 (Matos, 2002) e desde então, tem sido amplamente cultivada devido ao seu alto valor alimentício, principalmente das folhas, ricas em caroteno, ácido ascórbico e ferro (Makkar \& Becker, 1996; Bezerra et al., 2004). Os cotilédones e tegumentos das sementes de $M$. oleifera contêm proteínas com alta capacidade de coagulação e, portanto, são usados na purificação e clarificação de águas naturais (Gassenschmidt et al., 1995; Okuda et al., 2001; Bennett et al., 2003; Bezerra et al., 2004; Ghebremichael et al., 2005). Variadas propriedades terapêuticas são atribuídas à moringa, das quais incluem o uso como estimulante cardíaco e circulatório (Anwar et al., 2007; Faizi et al., 1994), antitumoral, antipirética, antiepilética, antiespasmódica, diurética, hepatoprotetora 
(Anwar et al., 2007), no combate a inflamações, hipertensão arterial (Anwar et al., 2007; Faizi et al., 1994; Guevara et al., 1999) e diarréia (Faizi et al., 1994; Bennett et al., 2003). Algumas atividades biológicas foram descritas na literatura para $M$. oleifera, dentre estas, destacam-se: antimicrobiana (Faizi et al., 1994; Matos, 2002), antitumoral (Guevara et al., 1999), hepatoprotetora (Bennett et al., 2003), antiespasmódica, diurética (Cáceres et al., 1992) e antifúngica (Chuang et al., 2007). Os relatos sobre estudos químicos de Moringa descrevem que plantas deste gênero são ricas em $\alpha$ - e $\gamma$-tocoferóis (SánchezMachado et al., 2006), glicosinolatos, nitrilas, glicosídeos (Guevara et al., 1999; Abdulkarim et al., 2004), quercetina, canferol (Anwar et al., 2007), ramnosídeos, isotiocianatos e esteróides (Eilert et al., 1981; Guevara et al., 1999). Chuang et al. (2007) relataram que os componentes principais do óleo essencial das folhas de Moringa oleifera eram: fitol $(7,66 \%)$, pentacosano $(17,41 \%)$ e hexacosano $(11,20 \%)$

O variado espectro de propriedades terapêuticas e nutricionais atribuídas a $M$. oleifera tem motivado vários grupos de pesquisa a estudar esta espécie. Neste trabalho são descritos os resultados obtidos na investigação química das folhas, frutos e flores de $M$. oleifera Lam.. O estudo do óleo essencial das flores e frutos está sendo relatado pela primeira vez para o gênero Moringa, bem como o isolamento da substância 4-hidroxifenil-acetonitrila.

\section{MATERIAIS E MÉTODOS}

\section{Instrumentação e procedimentos experimentais gerais}

Os pontos de fusão foram determinados em aparelho de microdeterminação MQPAF - 301 (Microquímica) provido de placa aquecedora modelo FP 52 e unidade de controle FP-5. As cromatografias de adsorção em coluna foram realizadas em colunas de vidro de comprimentos e diâmetros variados, com gel de sílica 60 (0,063-0,200 mm; 70-230 mesh, VETEC) como fase estacionária. Para as cromatografias em camada delgada analítica (CCD) foram utilizadas lâminas de vidro contendo gel de sílica $60 \mathrm{GF}_{254}$ Fluka. A revelação das placas CCD foi feita pela exposição das mesmas à lâmpada de irradiação na faixa do ultravioleta (UV), com dois comprimentos de onda (254 e $365 \mathrm{~nm}$ ), bem como, por aspersão das placas com solução de vanilina seguida de aquecimento por $5 \mathrm{~min}$ em placa aquecedora a aproximadamente $100{ }^{\circ} \mathrm{C}$.

Os espectros na região do IV foram obtidos em Espectrômetro Perkin Elmer, modelo FT-IR Espectrum 1000 utilizando pastilhas de $\mathrm{KBr}$. Os espectros de RMN ${ }^{1} \mathrm{H}$ e ${ }^{13} \mathrm{C}$ foram obtidos em espectrômetros Bruker Avance DPX-300 e DRX-500 operando na freqüência de hidrogênio-1 a $300,13 \mathrm{MHz}$ e a $500,13 \mathrm{MHz}$ e na freqüência do carbono a $75,47 \mathrm{MHz}$ e a $125,75 \mathrm{MHz}$, respectivamente. Os experimentos unidimensionais de $\mathrm{RMN}{ }^{13} \mathrm{C}$ foram efetuados sob desacoplamento total de hidrogênios. As amostras foram dissolvidas em $0,5 \mathrm{~mL}$ de $\mathrm{CDCl}_{3}$. Os deslocamentos químicos $(\delta)$ foram expressos em partes por milhão (ppm) e referenciados para $\mathrm{RMN}^{1} \mathrm{H}$ pelo pico do hidrogênio pertencente a fração de clorofórmio não deuterada $(\delta 7,27)$ e para $\mathrm{RMN}{ }^{13} \mathrm{C}$ pelo pico central do tripleto em $\delta 77,23$ do clorofórmio deuterado. O padrão de hidrogenação dos carbonos em RMN ${ }^{13} \mathrm{C}$ foi determinado a partir da utilização da técnica DEPT com o ângulo de nutação $(\theta)$ de $135^{\circ}$.

\section{Material vegetal}

As partes aéreas de $M$. oleifera Lam., Moringaceae foram coletadas no Setor de Horticultura do Campus do Pici da Universidade Federal do Ceará. A identificação botânica foi realizada pelo Prof. Edson P. Nunes do Departamento de Biologia da mesma universidade. A exsicata da planta encontra-se depositada no Herbário Prisco Bezerra do Departamento de Biologia da UFC, registrada sob número 38.195 .

\section{Obtenção e análise dos óleos essenciais}

As folhas (2,1 kg), as flores (95 g) e os frutos frescos (805 g) foram moídos e submetidos ao processo de arraste com vapor utilizando um aparelho tipo Clevenger durante $3 \mathrm{~h}$. Os óleos essenciais obtidos foram acondicionados em frascos de vidro e mantidos sob refrigeração até serem analisados. A análise dos óleos foi realizada utilizando cromatógrafo gasoso Shimadzu QP5050 equipado com coluna capilar de sílica fundida OV-5 (30 m; 0,25 mm; $0,25 \mu \mathrm{m}$ ) acoplado a espectrômetro de massa. O espectro de massa foi obtido com a voltagem de ionização de 70 $\mathrm{eV}$ (temperatura da fonte $250^{\circ} \mathrm{C}$ ). A rampa de temperatura foi programada de $40-180{ }^{\circ} \mathrm{C}$ a $4{ }^{\circ} \mathrm{C} / \mathrm{min}$ e de $180-280$ ${ }^{\circ} \mathrm{C}$ a $20^{\circ} \mathrm{C} / \mathrm{min}$ e mantido um isoterma por $7 \mathrm{~min}$. $\mathrm{O}$ gás de arraste utilizado foi o hélio num fluxo de $1,0 \mathrm{~mL} / \mathrm{min}$. Os constituintes foram identificados por comparação de seus espectros de massa com aqueles do banco de dados WILEY229 e confirmados por seus índices de retenção calculados em relação aos tempos de retenção de uma série homóloga de $n$-alcanos comparados com os dados relatados na literatura (Adams, 2001).

\section{Extração e isolamento dos constituintes químicos}

As folhas $(2,0 \mathrm{~kg})$ após extração dos óleos essenciais foram secas ao ar e maceradas com etanol:água 9:1 por 7 dias. O extrato obtido foi concentrado em evaporador rotatório à pressão reduzida, resultando em 49,3 g (2,5\%) de extrato (MOF-E). Uma alíquota de 44,3 $\mathrm{g}$ de MOF-E foi dissolvida em água destilada e extraída (3x $50 \mathrm{~mL}$ ) com clorofórmio (195 mg) e em seguida com acetato de etila $(920 \mathrm{mg})$. A fração clorofórmica foi cromatografada sobre gel de sílica e eluída com os solventes: éter de petróleo, acetona e metanol puros ou em 
misturas binárias em ordem crescente de polaridade. As subfrações 1-7 e 24, eluídas com éter de petróleo e éter de petróleo:acetona 1:3, forneceram, respectivamente, as substâncias $\mathbf{1}(4,4 \mathrm{mg})$ e $\mathbf{3}(56,1 \mathrm{mg})$. Uma alíquota de $877,4 \mathrm{mg}$ da fração acetato de etila foi submetida a cromatografia sobre gel de sílica e eluída com os solventes $n$-hexano, clorofórmio, acetato de etila e metanol, puros e em misturas binárias, em ordem crescente de polaridade. As frações obtidas foram analisadas por $\mathrm{CCD}$ e reunidas de acordo com suas semelhanças. A subfração 117-123 eluída com clorofórmio:acetato de etila 1:1 forneceu a substância $2(38,0 \mathrm{mg})$.

As cascas dos frutos secas (130 g) foram moídas e maceradas com $n$-hexano, resultando no extrato MOV-H $(1,7 \mathrm{~g})$ após concentração em evaporador rotatório. Uma alíquota de $934,3 \mathrm{mg}$ de MOV-H foi submetida a cromatografia sobre gel de sílica com éter de petróleo, clorofórmio, acetato de etila e metanol. A fração 6 (20,6 $\mathrm{mg}$ ) eluída com éter de petróleo foi identificada como sendo a substância 4 após análise espectrométrica (IV, RMN, EM).

As substâncias isoladas 1-4 foram caracterizados através dos métodos espectrométricos IV, RMN e EM, bem como, por comparação com os dados descritos na literatura (Adams, 2001; Faizi et al., 1994; Sekhar et al., 2002; Silverstein et al., 2005).

\section{RESULTADOS E DISCUSSÃO}

Fracionamentos cromatográficos sucessivos da fração clorofórmica do extrato etanólico das folhas de $M$. oleifera Lam., Moringaceae resultaram no isolamento das nitrilas 1 e 3 (Figura 1). A substância 2 foi isolada da fração acetato de etila do extrato etanólico das folhas eidentificadas a partir da análise de seus dados espectrométricos, bem como, pela comparação dos dados descritos na literatura (Faizi et al., 1994).

No espectro de $\mathrm{RMN}{ }^{13} \mathrm{C}$ de 2 foram observados quatorze sinais, dentre os quais, um sinal indicativo de carbono de nitrila em $\delta 120,0 \mathrm{ppm}$ e seis sinais associados aos carbonos do anel heterocíclico da ramnose em $\delta 100,1$ (C-1'); 72,4 (C-2'); 72,2 (C-3'); 74,0 (C-4'); 70,9 (C-5') e 18,2 (C-6') ppm. No mesmo espectro foram observados ainda sinais característicos de benzeno $p$-dissubstituído em $\delta 157,6$ (C-1), 118,2 (C-2,6), 130,5 (C-3,5) e 126,0 (C-4) ppm. O sinal em $\delta 22,9$ ppm foi atribuído ao carbono benzílico alfa à nitrila. No espectro de $\mathrm{RMN}{ }^{1} \mathrm{H}$ de 2 foram observados dois dubletos em $\delta 7,08(8,7 \mathrm{~Hz})$ e $7,29(8,7$ $\mathrm{Hz}$ ) ppm que foram inferidos a hidrogênios orto-acoplados num sistema AA'BB' de aromático $p$-dissubstituído. No mesmo espectro foi observado ainda um singleto em $\delta 3,82$ (H-7) ppm do grupo metileno benzílico alfa à nitrila, bem como, sinais característicos dos hidrogênios da ramnose, permitindo a identificação de $\mathbf{2}$ como a niazirina (Faizi et al., 1994). Os sinais observados nos espectros de RMN da substância 3 apresentaram-se bastante semelhantes aos observados nos espectros de 2 . No espectro de $\mathrm{RMN}^{1} \mathrm{H}$ de 3 foi observado um singleto largo indicativo de hidrogênio do carbono anomérico de carboidrato em $\delta$ 5,41 (H-1') ppm, bem como, os sinais dos hidrogênios dos carbonos oxigenados do sistema heterocíclico em $\delta 3,93$ ( $d d ; J 9,7 ; 3,5$ Hz; H-3'), 3,99 (dd; J 3,5; 1,8 Hz; H-2'), 4,87 ( $t ; J$ 9,7 Hz; $\mathrm{H}-4^{\prime}$ ) e 3,73 ( $q d ; J 9,7 ; 6,2 \mathrm{~Hz} ; \mathrm{H}-5$ ') ppm. O singleto em $\delta$ 2,04 ppm foi atribuído a um grupo acetil ligado ao carbono 4'. A posição deste grupo foi proposta a partir dos dados de deslocamento químico e constantes de acoplamento do H-4'comparadas com os dados da literatura (Faizi et al., 1994). Os hidrogênios orto-acoplados em $\delta 7,17$ (d; $J 8,6$ $\mathrm{Hz})$ e $6,99(d ; J 8,6 \mathrm{~Hz}) \mathrm{ppm}$ foram associados ao sistema AA'BB' de anel benzênico $p$-dissubstituído. No espectro de $\mathrm{RMN}{ }^{13} \mathrm{C}$ foram observados sinais característicos de carbonos de carboidratos em $\delta$ 99,5 (C-1'); 75,8 (C-4'); 72,0 (C-2'); 71,0 (C-3') e 68,4 (C-5') ppm para os carbonos monohidrogenados e em $\delta 18,8$ (C-6') ppm para o carbono metílico. A presença do grupo acetil neste composto foi justificada pelos sinais em $\delta 22,4$ e 173,1 ppm, indicativos do carbono metílico e da carbonila, respectivamente. Os carbonos aromáticos monohidrogenados foram observados em $\delta 116,9(\mathrm{C}-2,6)$ e 129,3 (C-3,5) ppm, e os não-hidrogenados em $\delta$ 156,0 (C-1) e 131,7 (C-4) ppm. A presença da nitrila foi proposta a partir do sinal em $\delta \mathrm{C}$ 119,7 (C-8) ppm e confirmada pela absorção característica da deformação axial $\mathrm{C} \equiv \mathrm{N}$ em $2260 \mathrm{~cm}^{-1}$ no espectro no infravermelho. Os dados obtidos para a substância 3 são comparáveis aos dados descritos na literatura para 4-Oacetil-alfa-ramnosídeos (Faizi et al., 1994) e sugeriram que 3 trata-se da 4-[4'-O-acetil- $\alpha$-L-ramnosiloxibenzil] nitrila denominada por niazirinina.

A substância 1 foi identificada como a 4-hidroxifenil-acetonitrila após comparação de seus dados de RMN com os dados observados para $\mathbf{2}$ e $\mathbf{3}$, bem como com os dados descritos na literatura (Faizi et al., 1994; Silverstein et al., 2005). No espectro de RMN ${ }^{1} \mathrm{H}$ em $\mathrm{CDCl}_{3}$ de $\mathbf{1}$ foram observados dois dubletos em $\delta$ $7,07(J 8,5 \mathrm{~Hz})$ e $6,75(J 8,5 \mathrm{~Hz})$ ppm característicos dos hidrogênios orto-acoplados do sistema AA'BB' no anel aromático $p$-dissubstituído, e ainda, um singleto em $\delta 3,60$ ppm indicativo do grupo metileno da acetonitrila alfasubstituída.
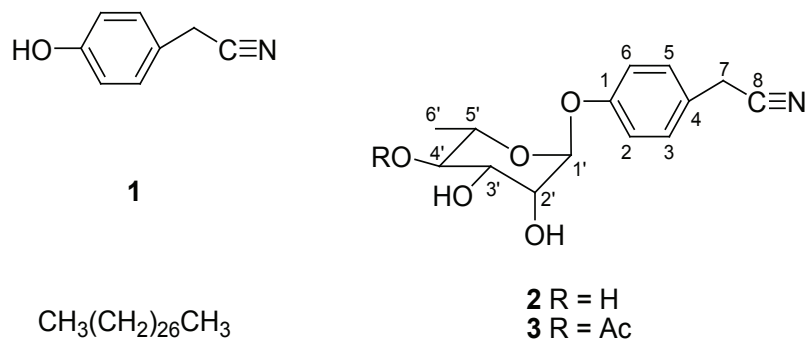

$\mathrm{CH}_{3}\left(\mathrm{CH}_{2}\right)_{26} \mathrm{CH}_{3}$

$3 R=A c$ 
A substância 4 foi isolada a partir do fracionamento cromatográfico do extrato hexânico das cascas dos frutos de M. oleifera. No espectro de $\mathrm{RMN}{ }^{13} \mathrm{C}$ de $\mathbf{4}$ foram observadas cinco linhas espectrais, dentre estas, uma em $\delta 14,1 \mathrm{ppm}$ indicativa de carbono metílico e as outras quatro relativas a carbonos metilênicos em $\delta 22,7 ; 29,4 ; 29,7$ e 32,9 ppm. No espectro de $\mathrm{RMN}{ }^{1} \mathrm{H}$ de $\mathbf{4}$ foram observados dois sinais característicos de hidrocarboneto saturado não ramificado em $\delta 0,91$ (t; $J 6,4 \mathrm{~Hz})$ e 1,28 (m) ppm. Os dados obtidos do espectro de massa (m/z 394, 379, 113, 99, 85, 71, 57, 43), acrescidos do p.f. $61,35^{\circ} \mathrm{C}$ contribuíram substancialmente para a proposição da estrutura do composto $\mathbf{4}$ como sendo o octacosano (Adams, 2001; Sekhar et al., 2002).

O estudo da composição química dos óleos essenciais das folhas, flores e frutos de M. oleifera, obtidos por arraste com vapor, foi realizado a partir das análises dos seus respectivos dados de CG-EM, levando-se em consideração os índices de retenção e as percentagens relativas de cada pico do cromatograma, bem como por comparação com os dados descritos na literatura (Adams, 2001). Foram identificados 21 componentes nestes óleos, distribuídos entre compostos não-terpenóides (ácidos, álcoois e hidrocarbonetos) e terpenóides oxigenados (monoterpenos, sesquiterpenos e diterpenos) (Tabela 1). O óleo essencial das folhas de M. oleifera mostrou ser rica em monoterpenos e sesquiterpenos oxigenados, dentre estes, o componente majoritário identificado foi o timol $(9,7 \%)$. Os componentes majoritários do óleo essencial das folhas foram fitol $(21,9 \%)$ e ácido hexadecanóico $(13,8 \%)$. De acordo com Chuang et al. (2007), no óleo essencial das folhas de M. oleifera foram identificados 44 componentes, dentre os quais, os constituintes principais foram: pentacosano $(17,41 \%)$, hexacosano $(11,20 \%)$ e fitol (7,66\%),jáoácidohexadecanóico(1,08\%)foidescrito como constituinte minoritário. O óleo essencial das flores de $\mathrm{M}$. oleifera em estudo mostrou ser rico em constituintes nãoterpenoídicos, principalmente tetracosano $(27,4 \%)$, acetato de hexadecila $(21,0 \%)$ e ácido hexadecanóico $(18,4 \%)$. Já no óleo dos frutos, predominaram os hidrocarbonetos não-terpenoídicos, destacando-se: docosano $(32,7 \%)$, tetracosano $(24,0 \%)$ e octacosano $(19,1 \%)$. A presença do octacosano no óleo essencial dos frutos corrobora com a identificação deste composto no extrato hexânico das cascas dos frutos descrita anteriormente.

Tabela 1. Composição percentual (\%) dos óleos essenciais das folhas, flores e frutos de M. oleifera Lam.

\begin{tabular}{|c|c|c|c|c|}
\hline Componentes $^{\mathrm{a}}$ & $\mathrm{IR}^{\mathrm{b}}$ & Folhas & Flores & Frutos \\
\hline linalool & 1103 & 2,9 & - & - \\
\hline$\alpha$-terpineol & 1190 & 2,4 & - & - \\
\hline geraniol & 1260 & 1,7 & - & - \\
\hline timol & 1300 & 9,7 & - & - \\
\hline metil-eugenol & 1410 & 2,3 & - & - \\
\hline$z$-isoelemincina & 1556 & 3,4 & - & - \\
\hline espatulenol & 1570 & 2,5 & - & - \\
\hline óxido de cariofileno & 1574 & 1,5 & - & - \\
\hline pentadecanol & 1779 & - & 10,5 & - \\
\hline hexa-hidrofarnesilacetona & 1789 & 8,5 & - & - \\
\hline octadecano & 1803 & 3,1 & - & 13,1 \\
\hline ácido hexadecanóico & 1822 & 13,8 & 18,4 & - \\
\hline nonadecano & 1848 & 3,7 & - & - \\
\hline fitol & 1850 & 21,9 & - & - \\
\hline acetato de hexadecila & 1950 & - & 21,0 & - \\
\hline eicosano & 1991 & - & - & 5,2 \\
\hline ácido 9,12-octadienóico & 2078 & 7,8 & 12,2 & - \\
\hline docosano & 2187 & 2,8 & & 32,7 \\
\hline tetracosano & 2433 & - & 27,4 & 24,0 \\
\hline octacosano & 2786 & - & - & 19,1 \\
\hline nonacosano & 2859 & 1,7 & 10,5 & - \\
\hline Total & & 89,7 & 100,0 & 94,1 \\
\hline
\end{tabular}




\section{AGRADECIMENTOS}

Ao CNPq e FUNCAP pelas bolsas concedidas e apoiofinanceiro(FUNCAP/CNPq/PPP). ÀCentralanalítica do Departamento de Química Orgânica e Inorgânica pelas análises por IV e CG/EM. Ao CENAUREMN pelos espectros de RMN.

\section{REFERÊNCIAS}

Abdulkarim SM, Long K, Lai OM, Muhammad SKS, Ghazali HM 2004. Some physico-chemical properties of Moringa oleifera seed oil extracted using solvent and aqueous enzymatic methods. J Food Chem 93: 253-256.

Adams RP 2001. Identification of essential oil components by gas chromatography/quadrupole mass spectroscopy. Illinois: Allured Pub Corp.

Anwar F, Latif S, Ashraf M, Gilani AH 2007. Moringa oleifera: A food plant with multiple medicinal uses. Phytoter Res 21: $17-25$.

Bennett RN, Mellon FA, Foidl N, Pratt JH, Dupont MS, Perkins L, Kroon PA 2003. Profiling glucosinolates and phenolics in vegetative and reproductive tissues of the multi-purpose trees Moringa oleifera L. (Horseradish Tree) and Moringa stenopetala L. J Agr Food Chem 51: 3546-3553.

Bezerra AME, Momenté VG, Medeiros Filho S 2004. Germinação de sementes e desenvolvimento de plântulas de moringa (Moringa oleifera Lam.) em função do peso da semente e do tipo de substrato. Hort Bras 22: 295-299.

Cáceres A, Saraiva A, Rizzo S, Zabala L, De Leon E, Nave F 1992. Pharmacological properties of Moringa oleifera. 2: Screening for antispasmodic, antiinflammatory and diuretic activity. $J$ Ethnopharmacol 36: 233-237.

Chuang PH, Lee CW, Chou JY, Murugan M, Shien BJ, Chen HM 2007. Anti-fungal activity of crude extracts and essential oil of Moringa oleifera Lam. Bioresource Technol 98: 232-236.

Eilert U, Wolters B, Nahrsted A 1981. The antibiotic principle of seeds of Moringa oleifera and Moringa stenopetala. Planta Med 42: 55-61.

Faizi S, Siddiqui BS, Saleem R, Siddiqui S, Aftab K 1994. Isolation and structure elucidation of new nitrile and mustard oil glycosides from Moringa oleifera and their effect on blood pressure. J Nat Prod 57: 1256-1261.

Gassenschmidt U, Jany KD, Tauscher B, Niebergall H 1995. Isolation and characterization of a flocculating protein from Moringa oleifera Lam. Biochim Biophys Acta 1243: 477-481.

Ghebremichael KA, Gunaratna KR, Henriksson H, Brumer H, Dalhammar G 2005. A simple purification and activity assay of the coagulant protein from Moringa oleifera seed. Water Res 39: 2338-2344.

Guevara AP, Vargas C, Sakurai H, Fujiwara Y, Hashimoto K, Maoka T, Kozuka M, Ito Y, Tokuda H, Nishino H 1999. An antitumor promoter from Moringa oleifera Lam. Mutat Res 440: 181-188.

Makkar HPS, Becker K 1996. Nutritional value and antinutritional components of whole and ethanol extracted Moringa oleifera leaves. Anim Feed Sci Tech 63: 211-228.

Matos FJA2002. Farmácias vivas: sistema de utilização de plantas medicinais projetado para pequenas comunidades. $4^{a} \mathrm{ed}$.
Fortaleza: UFC, SEBRAE/CE.

Okuda T, Baes AU, Nishijima W, Okada M 2001. Isolation and characterization of coagulant extracted from Moringa oleifera seed by salt solution. Water Res 35: 405-410.

Sánchez-Machado DI, López-Cervantes J, Vázquez NJR 2006. High-performace liquid chromatography method to measure $\alpha$ - and $\gamma$-tocopherol in leaves, flowers and fresh beans from Moringa oleifera. J Chromatogr A 1105: 111114.

Sekhar GC, Venkatesu P, Hofman T, Rao MVP 2002. Solid-liquid equilibria of long chain $n$-alkanes (C18-C28) in $N, N$ dimethylacetamide, Fluid Phase Equilibr 201: 219-231.

Silverstein RM, Webster FX, Kiemle DJ 2005. Spectrometric identification of organic compounds. USA: John Wiley \& Sons. 